\title{
Radium-223 in patients with metastatic castration-resistant prostate cancer: Efficacy and safety in clinical practice
}

\author{
ARSELA PRELAJ $^{1 *}$, SARA ELENA REBUZZI $^{2 *}$, FEDERICA BUZZACCHINO $^{1}$, CHIARA POZZI $^{1}$, \\ CARLA FERRARA $^{3}$, VIVIANA FRANTELLIZZI ${ }^{1}$, GIULIA ANNA FOLLACCHIO ${ }^{1}$, LIANA CIVITELLI ${ }^{1}$, \\ GIUSEPPE DE VINCENTIS $^{1}$, SILVERIO TOMAO ${ }^{1}$ and VINCENZO BIANCO ${ }^{1}$ \\ ${ }^{1}$ Department of Radiological, Oncological and Anatomo-Pathological Sciences, 'Sapienza' University of Rome, \\ Policlinico Umberto I, I-00161 Rome; ${ }^{2}$ Department of Medical Oncology, IRCCS San Martino IST, I-16132 Genoa; \\ ${ }^{3}$ Department of Public Health and Infectious Diseases, 'Sapienza' University of Rome, I-00185 Rome, Italy
}

Received April 3,2018; Accepted August 23, 2018

DOI: $10.3892 /$ ol.2018.9785

\begin{abstract}
Radium-223 has improved overall survival (OS) and reduced symptomatic skeletal events (SSE) in patients with metastatic castration-resistant prostate cancer (mCRPC) and bone metastases (ALSYMPCA trial). Our aim was to assess clinical and biochemical factors related to survival, safety and survival outcomes of Radium-223 in a clinical practice setting. We retrospectively analysed $32 \mathrm{mCRPC}$ patients treated with Radium-223, assessing bone scan, pain reduction, alkaline phosphatase (ALP) and prostate-specific antigen (PSA) response ( $\geq 30 \%$ reduction). At scintigraphic assessment, $41 \%$ had partial response with a disease control rate of $91 \% ; 56 \%$ had ALP response and $25 \%$ had PSA response; $41 \%$ had pain reduction with pain control of $72 \%$. Scintigraphic response and stability were correlated with longer median progression-free survival (mPFS) (13 and 12 vs. 6 months; $\mathrm{P}=0.002$ ) and $\mathrm{mOS}$ (16 and 12 vs. 6 months; $\mathrm{P}=0.003$ ). ALP response was associated with longer mPFS (13 vs. 12 months; $\mathrm{P}=0.2)$ and $\mathrm{mOS}(16$ vs. 12 months; $\mathrm{P}=0.2)$. PSA response was associated with longer mPFS (13 vs. 12 months; $\mathrm{P}=0.02$ ), whereas mOS could not be computed. Pain response and stability were associated with survival benefit according to mPFS (13 and 12 vs. 9 months) and mOS (both 16 vs. 12 months) without statistical significance. Baseline ALP <220 UI/1, Eastern Cooperative Oncology Group (ECOG) performance status 0 and absence of previous chemotherapy correlated with statistically significantly longer
\end{abstract}

Correspondence to: Dr Arsela Prelaj, Department of Radiological, Oncological and Anatomo-Pathological Sciences, 'Sapienza' University of Rome, Policlinico Umberto I, 324 Viale Regina Elena, I-00161 Rome, Italy

E-mail: arsela20@hotmail.it

*Contributed equally

Key words: radium-223, alkaline phosphatase, prostate-specific antigen, bone scan, metastatic castration-resistant prostate cancer, pain survival outcomes. Skeletal-related events (SRE) occurred in three patients and median time to first SRE was 9.5 months, mPFS was 12 months and mOS 14 months. G3-G4 toxicities developed in $16 \%$ of patients. Our results are in line with those reported in the pivotal trial and in other retrospective studies. In conclusion, Radium-223 was associated with high scintigraphic, biochemical and pain response rates and was tolerated well by most patients. Response to Radium-223 and better baseline factors correlated to longer survival in clinical practice experience as in the clinical trial setting.

\section{Introduction}

Most patients with metastatic castration-resistant prostate cancer (mCRPC) develop bone metastases, which are associated with an increased risk of pathologic bone fractures (both symptomatic and found incidentally), radiation or surgery to the bone, spinal cord compression which are called skeletal-related events (SRE) that occur in $20-50 \%$ of mCRPC patients. Indeed, these are the major causes of prostate cancer-specific morbidity, worsening of quality of life and death (1).

Radium-223 dichloride (Radium-223) is a novel targeted radioisotope that, as a bone-seeking calcium mimetic, selectively binds mineral hydroxyapatite of newly formed bone stroma in areas of increased metabolic activity as bone metastases (2). It emits high-energy alpha-particle radiation of short range ( $<100 \mathrm{~mm} ;<10$ cell diameters) that induces double-stranded DNA breaks with cytotoxic effects in target areas, limiting damage on surrounding normal tissue, particularly the bone marrow (3).

Based on previous phase II trials $(2,4,5)$, the efficacy and the safety of Radium-223 in mCRPC were demonstrated in the phase 3 Alpharadin in Symptomatic Prostate Cancer Patients (ALSYMPCA) trial, which investigated Radium-223 vs. placebo in patients with mCRPC with symptomatic bone metastases and no known visceral metastases who had previously received docetaxel or not (6). This trial showed that Radium-223 significantly improved median overall survival (mOS) and prolonged median time to first symptomatic skeletal events (SSE) compared with placebo, independently to prior exposure to docetaxel (7) 
and the use of bisphosphonates (8). The end-point SSE is similar to SRE, but includes only symptomatic pathologic fractures in addition to radiation or surgery to the bone and spinal cord compression. Notably, Radium-223 was associated with a favourable toxicity profile and a higher percentage of patients who experienced an improvement in quality of life $(6,9)$.

The survival benefit and the better safety profile of Radium-223 were the novel points compared to beta-emitting radiopharmaceuticals, such as Samarium-153 and Strontium-89/90.

The results of this pivotal study led to the regulatory approval from the American Food and Drug Administration and European Medicines Agency of Radium-223 for the treatment of mCRPC patients with symptomatic bone metastases. Given its effectiveness in both docetaxel-naïve and post-docetaxel patients, Radium-223 can be used as monotherapy both in first-line and in subsequent lines (7).

Recent studies confirmed the efficacy and the safety observed in the ALSYMPCA trial $(10,11)$ but more investigations on this novel agent in the clinical practice setting, outside the context of clinical trials, are needed.

The aim of this retrospective study was to assess clinical and biochemical factors related to survival and time to first SRE (tSRE) of Radium-223 in mCRPC patients in a clinical practice setting.

\section{Materials and methods}

Study population. From July 2015 to September 2017, we performed a retrospective analysis of all consecutive adult mCRPC patients treated with Radium-223 at the Policlinico Umberto I, Sapienza University of Rome.

CRPC was defined as a serum testosterone level of $<50 \mathrm{ng} / \mathrm{dl}$ following surgical or pharmaceutical castration. All patients had two or more symptomatic bone metastases detected by bone scan and no known visceral metastases, except for malignant lymphadenopathy with less than $3 \mathrm{~cm}$ in the short-axis diameter, an Eastern Cooperative Oncology Group (ECOG) performance status (PS) score of 0-2 and adequate haematological, liver and renal function.

Clinical data included patient characteristics [age, ECOG PS, baseline ALP, PSA and pain score by numeric rating scale (NRS)], tumour characteristics (Gleason score, number of bone metastases and presence or absence of lymph node metastases) and treatment information (median cycles and line of Radium-223, prior use of docetaxel and concomitant use of bisphosphonates/denosumab).

Treatment plan. All patients included in the analysis underwent treatment with Radium-223, which consisted of six intravenous injections of the radioisotope at a standard dose of $50 \mathrm{kBq} / \mathrm{kg}$ at four-week intervals until disease progression or unacceptable toxicity. The use of androgen deprivation therapy continued during Radium-223 treatment. Concomitant treatment with Abiraterone and Enzalutamide was not permitted. Patients were also receiving the best standard of care, including analgesics and glucocorticoids to control pain.

Response evaluation. Efficacy assessments included scintigraphic, biochemical and pain response. All patients were followed clinically by a multidisciplinary team and radiologically by bone scan. Patients had a technetium- $99 \mathrm{~m}$ bone scan before treatment, after three cycles and after all six cycles of Radium-223. The best scintigraphic result between the three assessments was considered the scintigraphic response. The bone-specific response was assessed as complete (CR) and partial (PR) response, stable (SD) and progression (PD) disease according to MD Anderson criteria (12). Overall response rate (ORR) was defined as the sum of $\mathrm{CR}$ and $\mathrm{PR}$ and disease control rate (DCR) as the sum of CR, PR and SD.

Biochemical and pain responses were evaluated with the relative change of ALP, PSA and NRS values, comparing the value at the end of the sixth cycle with the baseline value (13). A biological (ALP and PSA) response were defined as a reduction of $\geq 30 \%$ from the baseline value to the end of Radium-223 treatment. Pain response was defined as a decline of at least one range according to the NRS.

Statistical analysis. Survival analysis was conducted on the efficacy of Radium-223 in terms of progression-free survival (PFS) and OS. PFS was measured from the start of Radium-223 to diagnosis of PD evidenced by bone scan, death from any cause or last follow-up and calculated as median PFS (mPFS). OS was measured from the start of treatment to death from any cause or last follow-up. PFS and OS were estimated with a $95 \%$ confidence interval. Survival curves of PFS and OS were generated using the Kaplan-Meier method. Differences in PFS and OS were evaluated using the log-rank test (Mantel-Cox) for statistical significance, which was defined at the $\mathrm{P}<0.05$ level (14) using the SPSS program-Statistical Package for the Social Sciences. Time to the first SRE was defined as the time to first pathologic bone fractures and spinal cord compression (evaluated clinically and radiologically), radiation therapy and orthopaedic surgical intervention (1).

Subgroup analyses. Subgroup analyses were performed to assess survival outcomes based on scintigraphic response, biochemical (ALP and PSA) response ( $\geq 50$ and $\geq 30 \%$ ), pain response, baseline ALP levels ( $\pm 220 \mathrm{UI} / \mathrm{l})$, prior docetaxel use, concomitant bisphosphonates/denosumab and involvement of lymph node metastases. We did not assess a subgroup analyses according to Radium-223 line because of insufficient length of follow-up.

Toxicity evaluation. All adverse events were graded according to the Common Terminology Criteria for Adverse Events (CTCAE) version 4.03 (15). Toxicity assessment was performed at each cycle of treatment.

\section{Results}

Patient characteristics. Thirty-two mCRPC patients were included in the analysis. Patient, tumour and treatment characteristics are summarised in Table I.

The median age was 72 years (range 59-86 years) and median ECOG PS was 1 (range 0-2). All patients had a histological diagnosis of prostate cancer with a Gleason score $\geq 7$ in $75 \%$ of patients. Nineteen patients (59\%) had only bone metastases, whereas 13 patients $(41 \%)$ had also lymph 
Table I. Patient characteristics.

\begin{tabular}{lc}
\hline Characteristic & Value \\
\hline Median age, years (range) & $72(59-86)$ \\
ECOG performance status & \\
Median (range) & $1(0-2)$ \\
0 & $12(38)$ \\
1 & $9(28)$ \\
2 & $11(34)$
\end{tabular}

Gleason score at diagnosis

$\begin{array}{lr}\text { Median (range) } & 8(6-9) \\ \leq 7 & 8(25) \\ 8-10 & 24(75)\end{array}$

Metastases

Bone metastases

Bone and lymph node metastases

Extent of disease

$<6$

6-20

31 (97)

$>20$

Median PSA, ng/l (range)

Median ALP, U/l (range)

Baseline ALP, U/1

$<220$

$\geq 220$

Pain at baseline, NRS

Median (range)

$1-3$

4-6

$13(41)$

$11(34)$

Radium-223 treatment

Median cycles received, number (range)

Completed 6 cycles of Radium-223

Yes

No

Radium-223 treatment

First-line

Second-line

Other

Prior chemotherapy

Yes

No

Concomitant use of

biphosphonates/denosumab

Yes

21 (66)

Biphosphonates

15 (47)

Denosumab

No

$11(34)$

$\mathrm{n}=32$. Data are presented as $\mathrm{n}(\%)$ unless otherwise stated. ECOG, Eastern Cooperative Oncology Group; PSA, prostate-specific antigen; ALP, alkaline phosphatase; NRS, numerical rating scale.
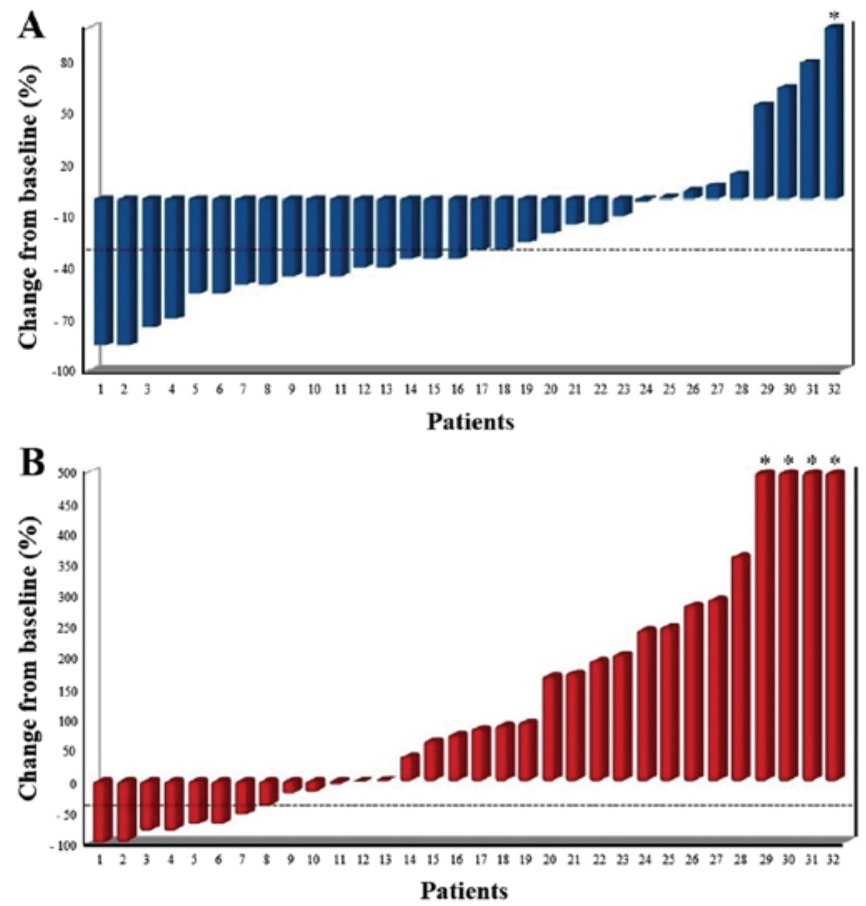

Figure 1. Waterfall plots of the percentage change in the (A) ALP and (B) PSA level from baseline to the end of Radium-223 treatment. The dotted line indicates a $30 \%$ decrease from baseline. "PSA value clipped. ALP, alkaline phosphatase; PSA, prostate-specific antigen.

node metastases. Most patients (97\%) had a number of bone metastases between 6 and 20 .

Radium-223 was administered as first-line therapy in 6 patients (19\%), as second-line in 14 patients (44\%) and in successive lines in 12 patients $(37 \%)$. The median number of cycles was 6 (range 2-6), and 29 patients (91\%) completed all six cycles. One patient discontinued the treatment after two cycles and 2 patients after four cycles because of death.

Fifteen patients (47\%) underwent chemotherapy before Radium-223, and $66 \%$ of patients had a concomitant use of bisphosphonates/denosumab. Median PSA was $88 \mathrm{~g} / 1$ (range 0.5-3847), median ALP was 163 U/l (range 53-1755) with baseline ALP $<220 \mathrm{UI} / 1$ in $63 \%$ of patients and median NRS score was 5 (range 1-10).

Activity evaluation. All patients were assessed for response analysis. At scintigraphic assessment, 13 patients (41\%) experienced PR and 16 patients (50\%) had SD with a DCR of $91 \%$.

At biochemical assessment with ALP, 18 patients $(56 \%)$ showed a biochemical response ( $\geq 30 \%$ reduction) with 8 patients (25\%) which showed an ALP reduction $\geq 50 \%$ (Fig. 1A).

At biochemical assessment with PSA, 8 patients $(25 \%)$ showed a biochemical response with 7 (22\%) which showed a PSA response $\geq 50 \%$ (Fig. 1B). Of the 24 patients with a PSA increase, only 2 had a scintigraphic progression, whereas 5 experienced a scintigraphic response, which can be evaluated as PSA flare up. Of these 5 patients, 2 patients also experienced a pain flare up.

At pain assessment, 16 patients $(50 \%)$ had pain response and 7 patients (22\%) had pain stability with a pain control of $72 \%$.

SREs occurred in 3 patients $(9 \%)$, two vertebral fractures and one external-beam radiation to relieve skeletal pain, with 

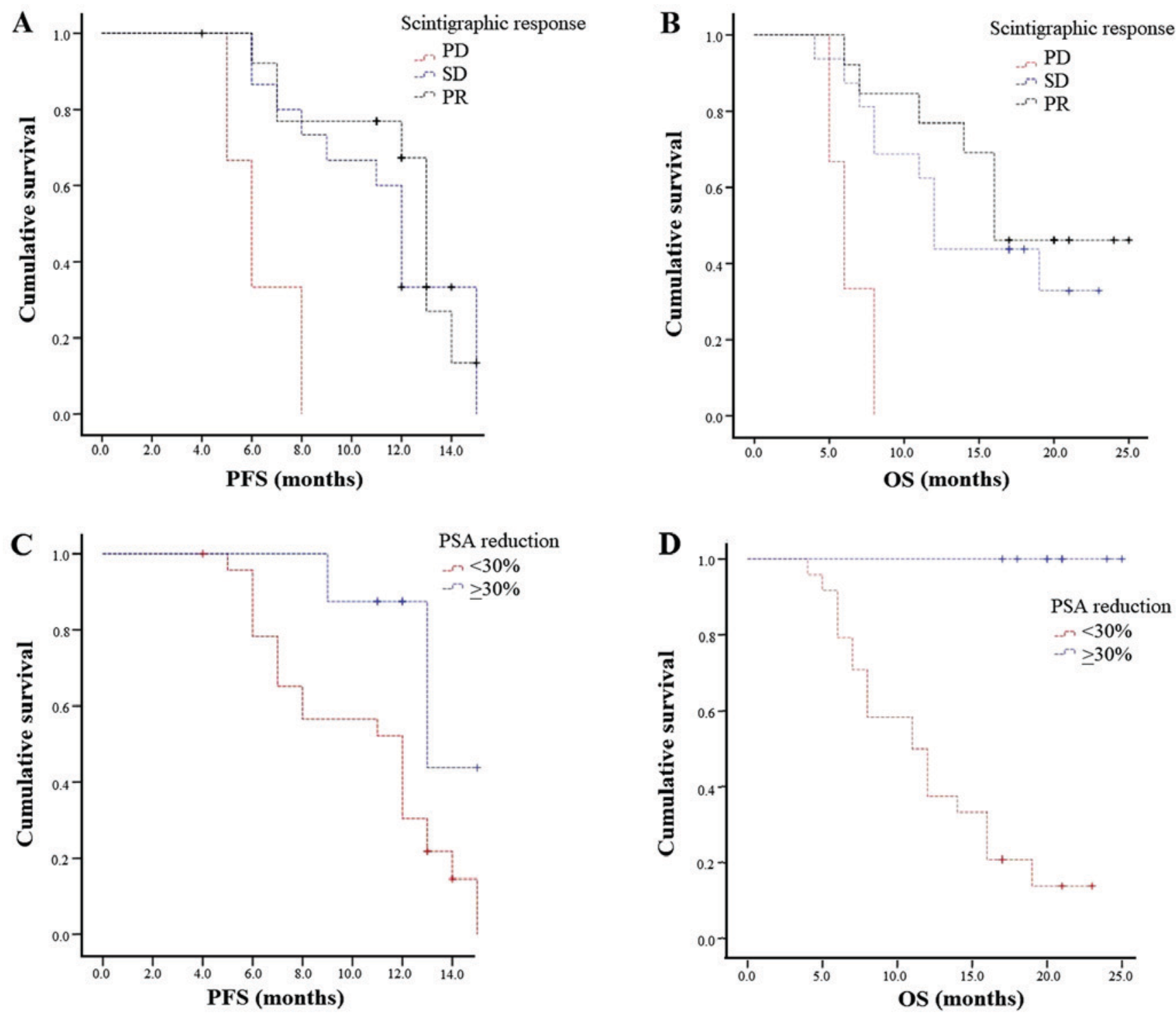

Figure 2. Kaplan-Meier curves of PFS and OS according to response. (A and B) Scintigraphic response, (C and D) PSA response. PFS, progression-free survival; OS, overall survival; PSA, prostate-specific antigen.

a median tSRE of 9.5 months (range 4-18). Median PFS was 12 months (95\% confidence interval (CI) 11-13 months) with a PFS rate at 1 year of $53 \%$, and mOS was 14 months $(95 \% \mathrm{CI}$ 10-18) with an OS rate at 1 year of $63 \%$.

Subgroup analyses. Scintigraphic response and stability were correlated with a statistically significant benefit in terms of mPFS (13 and 12 vs. 6 months; $\mathrm{P}=0.002)$ and $\mathrm{mOS}$ (16 and 12 vs. 6 months; $\mathrm{P}=0.003$; Fig. $2 \mathrm{~A}$ and $\mathrm{B}$ ).

According to PSA, biochemical response (both $\geq 30 \%$ and $\geq 50 \%$ ) was associated with longer mPFS (both 13 vs. 12 months; $\mathrm{P}=0.02$ and $\mathrm{P}=0.03$, respectively). Median OS was not computed because all cases were censored (Fig. 2C and D).

According to ALP, biochemical response (both $\geq 30$ and $\geq 50 \%$ ) was associated with longer mPFS (both 13 vs. 12 months; $\mathrm{P}=0.2$ and $\mathrm{P}=0.7$, respectively) and $\mathrm{mOS}$ ( $\geq 30 \%$ : 16 vs. 12 months; $\mathrm{P}=0.2$ and $\geq 50 \%$ : 14 vs. 11 months; $\mathrm{P}=0.7$; Fig. $3 \mathrm{~A}$ and $\mathrm{B}$ ).

Pain response was associated with survival benefit according to mPFS (13 vs. 12 months) and mOS (16 vs. 12 months) without statistical significance $(\mathrm{P}=0.4$ and $\mathrm{P}=0.9$, respectively). We also observed that pain stability was associated with similar survival outcomes compared to pain response, both associated with longer mPFS and mOS compared to pain worsening (mPFS: 13 vs. 12 vs. 9 months; $\mathrm{P}=0.6$ and mOS: both 16 vs. 11 months; $\mathrm{P}=0.7$ ).

Patients with baseline ALP $<220 \mathrm{UI} / 1$ had a statistically significantly longer mPFS (13 vs. 7 months, $\mathrm{P}=0.002$ ) and mOS (16 vs. 7 months, $\mathrm{P}=0.04)$ than those with baseline ALP $\geq 220 \mathrm{UI} / 1$ (Fig. 3C and D).

Patients with ECOG PS 0 experienced higher mPFS (14 vs. 12 months; $\mathrm{P}=0.01$ ) and mOS (Not reached-11 months; $\mathrm{P}=0.009$; Fig. 4A and B). Those with both bone and lymph node metastases had similar survival outcomes compared to bone metastases patients. Patients not previously treated with chemotherapy experienced statistically significantly longer PFS (14 vs. 11 months; $\mathrm{P}=0.007$ ) and mOS (not reached 12 months; $\mathrm{P}=0.02$; Fig. $4 \mathrm{C}$ and $\mathrm{D})$. The concomitant use of bisphosphonates/denosumab did not affect survival outcomes in terms of OS and PFS. 

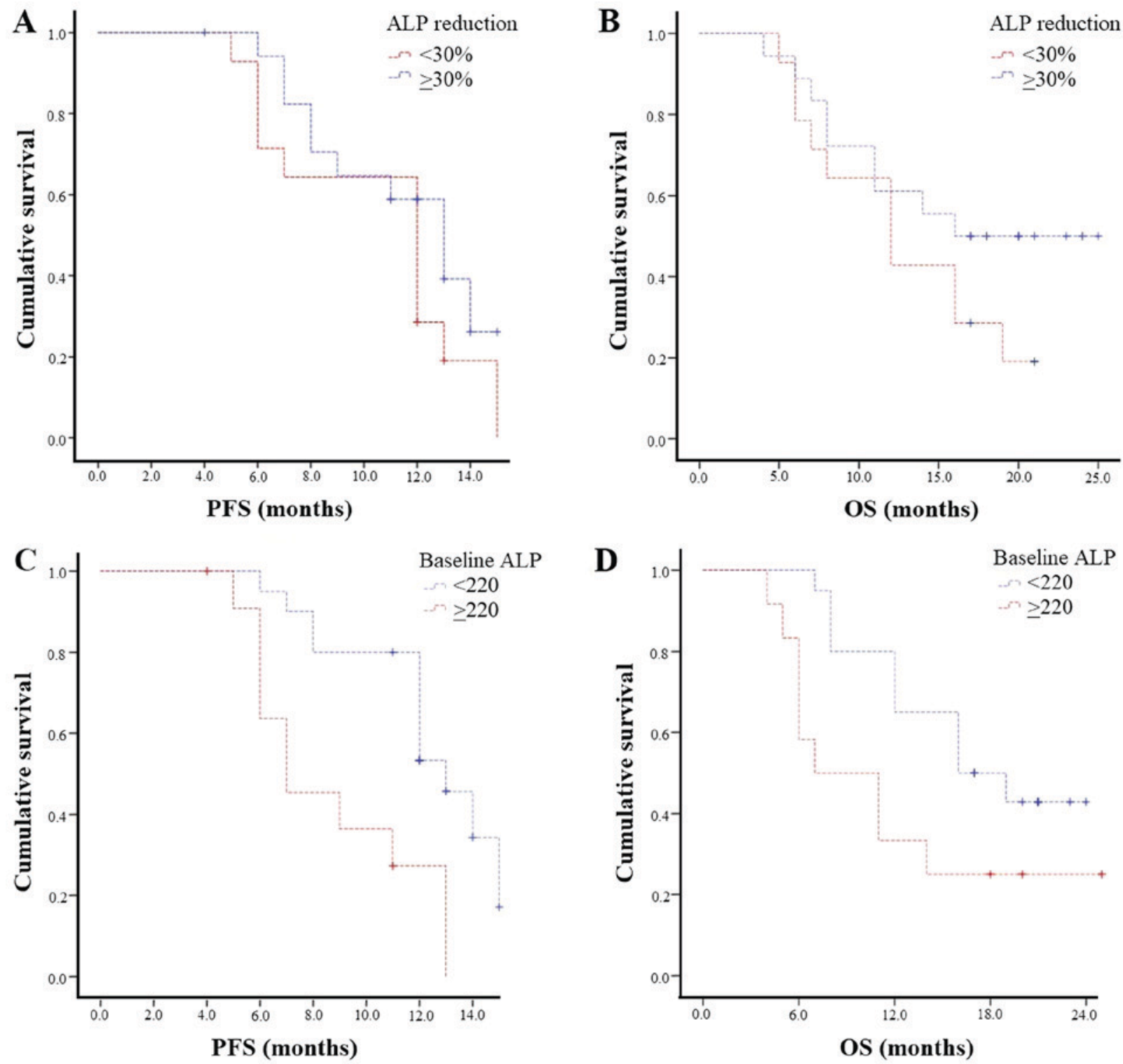

Figure 3. Kaplan-Meier curves of PFS and OS according to (A and B) ALP response and (C and D) baseline ALP. PFS, progression-free survival; OS, overall survival; ALP, alkaline phosphatase.

All the results of the subgroup analyses are summarised in Table II.

Toxicity evaluation. All 32 patients were evaluated for safety (Table III). Radium-223 was generally well tolerated with grade 1-2 haematologic toxicities in only $9 \%$ of patients. Grade 1-2 gastrointestinal toxicities were observed in $19 \%$ of patients and included hypertransaminasemia (3\%), diarrhoea (9\%), constipation (3\%) and nausea (3\%); grade 1-2 creatinine increased and oedema of limbs were both developed in $6 \%$ of patients. Grade 3 toxicities were observed in $16 \%$ of patients and included anaemia (13\%) and thrombocytopenia (3\%). No grade 4 adverse events were observed. None of the patients discontinued for toxicity.

\section{Discussion}

Radium-223 was approved for the treatment of mCRPC patients based on its OS benefit and safety profile demonstrated in the registrational ALSYMPCA trial (6). In this phase 3 trial, Radium-223 significantly prolonged mOS of 3.6 months $(14.9$ vs. 11.3 months, hazard ratio $(\mathrm{HR})=0.70 ; \mathrm{P}<0.001)$ compared to placebo (6). Both subgroups previously treated $(\mathrm{HR}=0.70 ; \mathrm{P}=0.002)$ and not previously treated with docetaxel (HR=0.69; $\mathrm{P}=0.01)$ showed improved OS (7). Radium-223 prolonged median time to first SSE compared to placebo (15.6 vs. 9.8 months, $\mathrm{HR}=0.66 ; \mathrm{P}<0.001)(6)$ regardless of prior docetaxel therapy, baseline ALP level and current use of bisphosphonates (8). It also significantly prolonged median time to ALP increase (7.4 vs. 3.8 months; $\mathrm{P}<0.001)$ and a significant number of patients experienced a total ALP response $(\geq 30 \%$ reduction from baseline) (47\% vs. $3 \%$; $\mathrm{P}<0.001)$ and an ALP normalisation (34\% vs. $1 \%$; $\mathrm{P}<0.001)$ compared to placebo (6). The PSA responses ( $\geq 30 \%$ reduction from baseline) were less pronounced compared to ALP level (16\% vs 6\%; P<0.001) (6). In this way, ALP has emerged as the leading biomarker for Radium-223 treatment response (16). A low incidence of grade 3-4 adverse events (56\% vs. $62 \%)$ and of study-drug discontinuation due to 

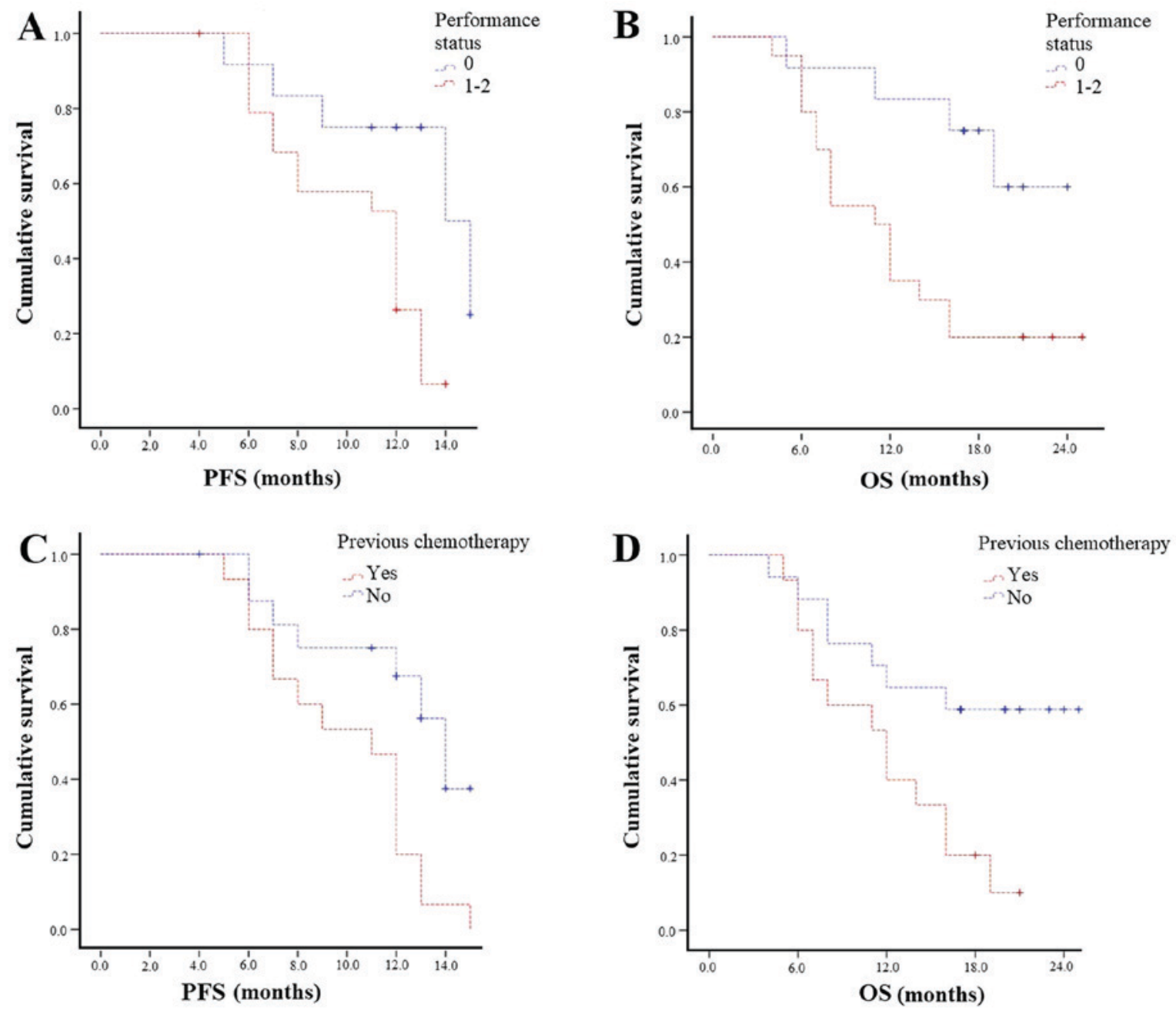

Figure 4. Kaplan-Meier curves of PFS and OS according to (A and B) performance status and (C and D) previous chemotherapy. PFS, progression-free survival; OS, overall survival.

toxicity ( $16 \%$ vs. $21 \%$ ) was shown, especially in patients with a low extent of disease and no prior docetaxel treatment $(7,17)$.

Our study is a retrospective analysis of mCRPC patients treated with Radium-223 in a clinical practice setting. Our clinical experience is in line with the results of the ALSYMPCA trial in terms of efficacy and safety. Compared to the ALSYMPCA trial, our court of patients had similar characteristics, except for a better performance status (ECOG PS 0: $38 \%$ vs. $27 \%$ ), lower previous chemotherapies ( $47 \%$ vs. $57 \%$ ), lower severe pain ( $25 \%$ vs. $32 \%$ ), lower median PSA ( 88 vs. $146 \mu \mathrm{g} / \mathrm{l}$ ) and the absence of massive bone metastases ( $>20$ metastases: $0 \%$ vs. 32\%). Most of our patients (63\%), in fact, were treated with Radium-223 in an early setting as first- or second-line. For this reason, $91 \%$ of patients completed all six cycles of treatment, a percentage higher than that reported in the ALSYMPCA trial (6) and in other retrospective trials $(11,13,18-24)$ (Table IV).

We observed a significant percentage of ALP response (56\% of patients) associated with survival benefit but without statistical significance. However, baseline ALP <220 correlated with longer survival outcomes in terms of mPFS and mOS with statistical significance. These results on ALP are in line with those of other trials (Table IV), reflecting the potential role of ALP as a predictor of survival in mCRPC patients treated with Radium-223 (2). On the other hand, we observed a lower percentage of PSA response (25\%), which is higher than that reported in other trials (range 10-27\%), associated with longer mPFS with statistical significance. The primary aim of Radium-223 is to target bone metastases and therefore ALP, which is a biomarker of osteoblast activity, should be preferred over PSA as a biomarker of the efficacy of Radium-223 $(2,4,25,26)$. In fact, the increase of PSA may have resulted from the development of lymph node or visceral metastases not influenced by Radium-223.

The best correlation observed in our study was between scintigraphic response and survival outcomes: patients with a scintigraphic response/stability had a longer PFS $(\mathrm{P}=0.002)$ and $\mathrm{OS}(\mathrm{P}=0.003)$. Bone scan response was not described in the ALSYMPCA trial and in the majority of clinical trials on Radium-223 presented in the literature (Table IV) although it is the main radiological exam of bone metastases in clinical practice. According to the results observed and the natural target of Radium-223, systematic bone scan evaluations should be the main parameter, in association with ALP, to evaluate the response to the radionuclide treatment.

According to bone pain, we observed pain response in $41 \%$ of patients and pain control in $75 \%$ of patients, which are associated with better survival outcomes. Even though preliminary 
Table II. Subgroup analysis.

\begin{tabular}{|c|c|c|c|c|c|}
\hline Variable & Patients n $(\%)$ & Median PFS, months & $\mathrm{P}$-value & Median OS, months & $\mathrm{P}$-value \\
\hline ALP baseline (UI/1) & & & 0.002 & & 0.04 \\
\hline$<220$ & $20(63)$ & 13 & & 16 & \\
\hline$>220$ & $12(37)$ & 7 & & 7 & \\
\hline ALP response & & & 0.2 & & 0.2 \\
\hline$\geq 30 \%$ & $18(56)$ & 13 & & 16 & \\
\hline$<30 \%$ & $14(44)$ & 12 & & 12 & \\
\hline ALP response & & & 0.7 & & 0.7 \\
\hline$\geq 50 \%$ & $8(25)$ & 13 & & 14 & \\
\hline$<50 \%$ & $24(75)$ & 12 & & 11 & \\
\hline PSA response & & & 0.02 & a & $<0.0001$ \\
\hline$\geq 30 \%$ & $8(25)$ & 13 & & & \\
\hline$<30 \%$ & $24(75)$ & 12 & & & \\
\hline PSA response & & & 0.03 & a & 0.001 \\
\hline$\geq 50 \%$ & $7(22)$ & 13 & & & \\
\hline$<50 \%$ & $25(78)$ & 12 & & & \\
\hline Scintigraphic response & & & 0.002 & & 0.003 \\
\hline PR & $13(41)$ & 13 & & 16 & \\
\hline $\mathrm{SD}$ & $16(50)$ & 12 & & 12 & \\
\hline $\mathrm{PD}$ & $3(9)$ & 6 & & 6 & \\
\hline Pain assessment & & & 0.6 & & 0.7 \\
\hline Response & $16(50)$ & 13 & & 16 & \\
\hline Stability & $7(22)$ & 12 & & 16 & \\
\hline Worsening & $9(28)$ & 9 & & 11 & \\
\hline ECOG PS & & & 0.01 & & 0.009 \\
\hline 0 & $12(37)$ & 14 & & NR & \\
\hline $1-2$ & $20(63)$ & 12 & & 11 & \\
\hline Previous chemotherapy & & & 0.007 & NR & 0.02 \\
\hline No & $17(53)$ & 14 & & 12 & \\
\hline Yes & $15(47)$ & 12 & & & \\
\hline
\end{tabular}

${ }^{a}$ No statistics were computed because all cases were censored. ALP, alkaline phosphatase; PSA, prostate-specific antigen; PR, partial response; $\mathrm{SD}$, stable disease; PD, progression disease; PS, performance status; PFS, progression-free survival; OS, overall survival; NR, not reached.

Table III. Toxicities of Radium-223 according to the CTCAE (version 4.03).

\begin{tabular}{|c|c|c|c|c|}
\hline Chemotherapy-related toxicity & Grade 1 & Grade 2 & Grade 3 & Grade 4 \\
\hline Anaemia & $3(9)$ & - & $4(13)$ & - \\
\hline Thrombocytopenia & - & - & $1(3)$ & - \\
\hline Hypertransaminasemia & $1(3)$ & - & - & - \\
\hline Creatinine increased & $2(6)$ & - & - & - \\
\hline Diarrhoea & $1(3)$ & $2(6)$ & - & - \\
\hline Constipation & $1(3)$ & - & - & - \\
\hline Nausea & $1(3)$ & - & - & - \\
\hline Oedema of limbs & - & $2(6)$ & - & - \\
\hline
\end{tabular}

studies (4) and post-hoc analyses showed that Radium-223 treatment was associated with a better pain relief (30\% vs.
20\%; $\mathrm{P}=0.01$ ) (9), the ALSYMPCA trial was not designed to be a pain-palliative treatment (27). 


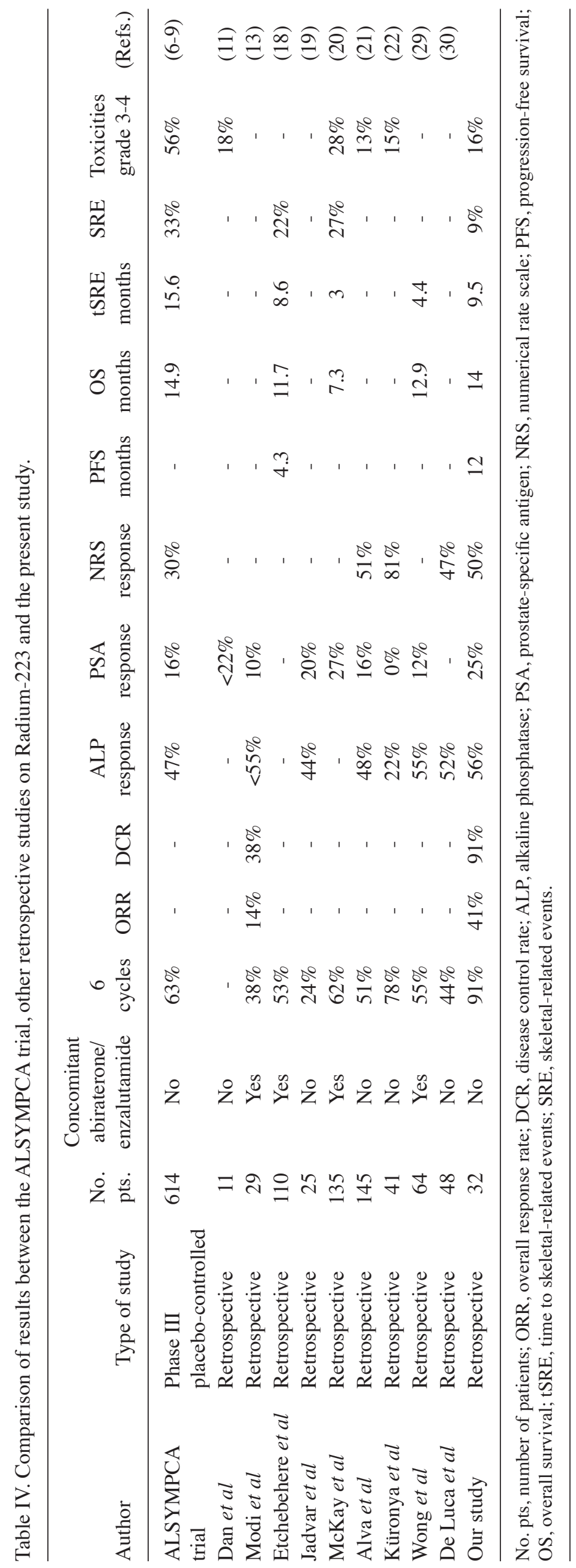


PSA and pain relief, therefore, should not be used as a surrogate measure of Radium-223 efficacy nor alter the decision to administer all six radionuclide injections, the recommended regimen for survival benefit (28).

Therefore, scintigraphic and biochemical responses and baseline factors that reflected a less aggressive disease (such as ALP <220, ECOG PS 0 and the absence of previous chemotherapy) were associated with better survival with statistical significance.

The mOS observed in our population was similar to that reported in the ALSYMPCA trial, which was the primary end-point of the study, confirming the benefit in survival of Radium-223 also in clinical practice experiences. In the pivotal trial and all the post-hoc analyses, OS was not supported by PFS data due to the unknown direct anti-tumour effect of Radium-223, which is reflected in the marginal effect on PSA. The choice of the secondary end-points (ALP and tSRE) and their clinical relevance were reflected by the pharmacodynamics of Radium-223, which is focused on bone disease.

The safety results observed in our study were satisfactory, with a lower percentage of grade 3-4 adverse events (16\%) compared to the ALSYMPCA trial and similar to other retrospective analyses (Table IV).

Some limitations are evident in this study because it represents a relatively small and single-institution retrospective analysis based on clinical experience. Given the small sample size, many evaluations described did not reach statistical significance. Despite these limitations, the heterogeneity of our population provides a broad perspective on the use of Radium-223 in real-life practice and provides interesting observations on efficacy, survival outcomes and tolerability outside prospective randomised trials.

Further analyses on the use of Radium-223 in clinical practice settings in combination or sequence with other agents $(29,30)$ and on the identification of clinical and biochemical predictors of Radium-223 benefit are needed. Having established the efficacy of Radium-223 in metastatic CRPC, future trials would focus on its earlier use in non-advanced and castration sensitive metastatic prostate cancer as well as its efficacy in patients with other primary bone-metastatic cancers.

In conclusion, our retrospective study reported that clinical and biochemical prognostic factors, both at baseline and after treatment, correlated with better prognosis. It also showed that Radium-223 is a valid treatment in terms of efficacy and safety in $\mathrm{MCRPC}$ patients in the real-life clinical practice as well as in the clinical trial setting.

\section{Acknowledgements}

Not applicable.

\section{Funding}

No funding was received.

\section{Availability of data and materials}

The datasets used and/or analysed during the current study are available from the corresponding author on reasonable request.

\section{Authors' contributions}

AP and SER were the major contributors in writing the manuscript, analysing and interpreting the patient data. FB, CP, CF, $\mathrm{VF}$ and GAF were involved in the acquisition, analysis and interpretation of patient data. GDV, ST and VB were involved in analysis and interpretation of patient data, writing the manuscript and revising it critically for important intellectual content. All authors read and approved the final manuscript.

\section{Ethics approval and consent to participate}

All procedures performed in studies involving human participants were in accordance with the ethical standards of the institutional and/or national research committee and with the 1964 Declaration of Helsinki and its later amendments or comparable ethical standards. Written informed consent was obtained from all individual participants included in the study.

\section{Patient consent to participate}

Written informed consent was obtained from all individual participants included in the study.

\section{Competing interests}

The authors declare that they have no competing interests.

\section{References}

1. DePuy V, Anstrom KJ, Castel LD, Schulman KA, Weinfurt KP and Saad F: Effects of skeletal morbidities on longitudinal patient-reported outcomes and survival in patients with metastatic prostate cancer. Support Care Cancer 15: 869-876, 2007.

2. Nilsson S, Franzén L, Parker C, Tyrrell C, Blom R, Tennvall J, Lennernäs B, Petersson U, Johannessen DC, Sokal M, et al: Bone-targeted radium-223 in symptomatic, hormone-refractory prostate cancer: A randomised, multicentre, placebo-controlled phase II study. Lancet Oncol 8: 587-594, 2007.

3. Kerr C: (223)Ra targets skeletal metastases and spares normal tissue. Lancet Oncol 3: 453, 2002.

4. Nilsson S, Strang P, Aksnes AK, Franzèn L, Olivier P, Pecking A, Staffurth J, Vasanthan S, Andersson C and Bruland ØS: A randomized, dose-response, multicenter phase II study of radium-223 chloride for the palliation of painful bone metastases in patients with castration-resistant prostate cancer. Eur J Cancer 48: 678-686, 2012.

5. Parker CC, Pascoe S, Chodacki A, O'Sullivan JM, Germá JR, O'Bryan-Tear CG, Haider T and Hoskin P: A randomized, double-blind, dose-finding, multicenter, phase 2 study of radium chloride ( $\mathrm{Ra} 223$ ) in patients with bone metastases and castration-resistant prostate cancer. Eur Urol 63: 189-197, 2013.

6. Parker C, Nilsson S, Heinrich D, Helle SI, O'Sullivan JM, Fosså SD, Chodacki A, Wiechno P, Logue J, Seke M, et al: Alpha emitter radium-223 and survival in metastatic prostate cancer. $\mathrm{N}$ Engl J Med 369: 213-223, 2013.

7. Hoskin P, Sartor O, O'Sullivan JM, Johannessen DC, Helle SI, Logue J, Bottomley D, Nilsson S, Vogelzang NJ, Fang F, et al: Efficacy and safety of radium-223 dichloride in patients with castration-resistant prostate cancer and symptomatic bone metastases, with or without previous docetaxel use: A prespecified subgroup analysis from the randomised, double-blind, phase 3 ALSYMPCA trial. Lancet Oncol 15: 1397-1406, 2014.

8. Sartor O, Coleman R, Nilsson S, Heinrich D, Helle SI, O'Sullivan JM, Fosså SD, Chodacki A, Wiechno P, Logue J, et al: Effect of radium-223 dichloride on symptomatic skeletal events in patients with castration-resistant prostate cancer and bone metastases: Results from a phase 3, double-blind, randomised trial. Lancet Oncol 15: 738-746, 2014. 
9. Nilsson S, Cislo P, Sartor O, Vogelzang NJ, Coleman RE, O'Sullivan JM, Reuning-Scherer J, Shan M, Zhan L and Parker C: Patient-reported quality-of-life analysis of radium-223 dichloride from the phase III ALSYMPCA study. Ann Oncol 27: 868-874, 2016.

10. Saad F, Carles J, Gillessen S, Heinrich D, Gratt J, Miller K, Sten Nilsson S, O'Sullivan J, Tucci M and Heidenreich A: Radium-223 in an international early access program (EAP): Effects of concomitant medication on overall survival in metastatic castration-resistant prostate cancer (mCRCP) patients (Internet). J Clin Oncol 33: 5034, 2015.

11. Dan TD, Eldredge-Hindy HB, Hoffman-Censits J, Lin J, Kelly WK, Gomella LG, Lallas CD, Trabulsi EJ, Hurwitz MD, Dicker AP and Den RB: Hematologic toxicity of concurrent administration of radium-223 and next-generation antiandrogen therapies. Am J Clin Oncol 40: 342-347, 2017.

12. Costelloe CM, Chuang HH, Madewell JE and Ueno NT: Cancer response criteria and bone metastases: RECIST 1.1, MDA and PERCIST. J Cancer 1: 80-92, 2010.

13. Modi D, Hwang C, Mamdani H, Kim S, GayarH, Vaishampayan U, Joyrich R and Heath EI: Radium-223 in heavily pretreated metastatic castrate-resistant prostate cancer. Clin Genitourin Cancer 14: 373-380.e2, 2016.

14. Kaplan EL and Meier P: Nonparametric estimation from incomplete observations. J Am Stat Assoc 53: 457-481, 1958.

15. National Cancer Institute: Common Terminology Criteria for Adverse Events (CTCAE) v4.03. http://ctep.cancer.gov. Accessed January 28, 2017.

16. Nguyen NC, Shah M, Appleman LJ, Parikh R and Mountz JM: Radium-223 therapy for patients with metastatic castrate-resistant prostate cancer: An update on literature with case presentation. Int J Mol Imaging 2016: 2568031, 2016.

17. Vogelzang NJ, Coleman RE, Michalski JM, Nilsson S, O'Sullivan JM, Parker C, Widmark A, Thuresson M, Xu L, Germino J and Sartor O: Hematologic safety of radium-223 dichloride: Baseline prognostic factors associated with myelosuppression in the ALSYMPCA Trial. Clin Genitourin Cancer 15: 42-52.e8, 2017.

18. Etchebehere EC, Milton DR, Araujo JC, Swanston NM, Macapinlac HA and Rohren EM: Factors affecting (223)Ra therapy: Clinical experience after 532 cycles from a single institution. Eur J Nucl Med Mol Imaging 43: 8-20, 2016.

19. Jadvar H, Challa S, Quinn DI and Conti PS: One-year postapproval clinical experience with radium-223 dichloride in patients with metastatic castrate-resistant prostate cancer. Cancer Biother Radiopharm 30: 195-199, 2015.

20. McKay RR, Jacobus S, Fiorillo M, Ledet EM, Cotogna PM, Steinberger AE, Jacene HA, Sartor O and Taplin ME: Radium-223 use in clinical practice and variables associated with completion of therapy. Clin Genitourin Cancer 15: e289-e298, 2017.
21. Alva A, Nordquist L, Daignault S, George S, Ramos J, Albany C, Isharwal S, McDonald M, Campbell G, Danchaivijitr P, et al: Clinical correlates of benefit from radium-223 therapy in metastatic castration resistant prostate cancer. Prostate 77: 479-488, 2017.

22. Küronya Z, Sinkovics I, Ágoston P, Bíró K, Bodrogi I, Böde I, Dank M, Gyergyay F, Vajdics T, Kolonics Z, et al: A retrospective analysis of the first $41 \mathrm{mCRPC}$ patients with bone pain treated with radium-223 at the national institute of oncology in hungary. Pathol Oncol Res 23: 777-783, 2017.

23. Cha TL, Wu TT, Vogelzang NJ, Huang CY, Huang SP, Lin C, Ou YC, Pang ST, Shen DH, Wu WJ and Chang WY: Optimal usage of radium-223 in metastatic castration-resistant prostate cancer. J Formos Med Assoc 116: 825-836, 2017.

24. Hague $\mathrm{C}$ and Logue JP: Clinical experience with radium-223 in the treatment of patients with advanced castrate-resistant prostate cancer and symptomatic bone metastases. Ther Adv Urol 8: 175-180, 2016.

25. Tomblyn M, Nilsson S, Vogelzang N, Sartor AO, Cislo P, Van Gool R, Aksnes AK and Parker C: 714 Pain and quality of life $(\mathrm{QoL})$ analyses from the phase 3 randomized ALSYMPCA study with radium-223 dichloride (Ra-223) in castration-resistant prostate cancer (CRPC) patients with bone metastases. J Urol 189: e293, 2013.

26. Nilsson S: Radionuclide therapies in prostate cancer: Integrating radium-223 in the treatment of patients with metastatic castration-resistant prostate cancer. Curr Oncol Rep 18: 14, 2016.

27. Nevedomskaya E, Baumgart SJ and Haendler B: Recent advances in prostate cancer treatment and drug discovery. Int J Mol Sci 19: pii: E1359, 2018

28. Saad F, Carles J, Gillessen S, Heidenreich A, Heinrich D, Gratt J, Lévy J, Miller K, Nilsson S, Petrenciuc O, et al: Radium-223 and concomitant therapies in patients with metastatic castration-resistant prostate cancer: An international, early access, open-label, single-arm phase 3b trial. Lancet Oncol 17: 1306-1316, 2016.

29. Wong WW, Anderson EM, Mohammadi H,Daniels TB, Schild SE, Keole SR, Choo CR, Tzou KS, Bryce AH, Ho TH, et al: Factors associated with survival following radium-223 treatment for metastatic castration-resistant prostate cancer. Clin Genitourin Cancer 15: e969-e975, 2017.

30. De Luca R, Costa RP, Tripoli V, Murabito A and Cicero G: The clinical efficacy of radium-223 for bone metastasis in patients with castration-resistant prostate cancer: An italian clinical experience. Oncology 94: 161-166, 2018.

This work is licensed under a Creative Commons Attribution-NonCommercial-NoDerivatives 4.0 International (CC BY-NC-ND 4.0) License. 